\title{
The role of "fear of corticosteroids" in nonparticipation in early intervention with inhaled corticosteroids in asthma and COPD in general practice
}

\author{
P.M. van Grunsven*, C.P. van Schayck*, H.J.M. van Kollenburg*, K. van Bosheide*, \\ H.J.M. van den Hoogen*, J. Molema**, C. van Weel*
}

The role of "fear of corticosteroids" in nonparticipation in early intervention with inhaled corticosteroids in asthma and COPD in general practice. P.M. Van Grunsven, C.P. van Schayck, H.J.M van Kollenburg, K. van Bosheide, H.J.M. van den Hoogen, J. Molema, C. van Weel. CERS Journals Ltd 1998.

ABSTRACT: Treatment of chronic airflow obstruction with inhaled corticosteroids at an early stage has been shown to preserve the lung function. We tested the hypothesis that "fear of corticosteroids" may be an important reason for nonparticipation in the Detection, early Intervention and Monitoring programme on Chronic obstruction pulmonary disease (COPD) and Asthma ("DIMCA") project.

One thousand seven hundred and forty nine adult subjects from 10 general practices were invited to participate in the several parts of the "DIMCA" programme. Refusers were questioned about the reason(s) for nonparticipation.

Together the screening, monitoring and three drug interventions of the study showed on average $25-35 \%$ refusers. The most frequent reasons for nonparticipation were absence of pulmonary symptoms and lack of time. For those invited to take part in one of the three drug interventions, "dislike of medication" was the most important reason for nonparticipation $(33,45$ and $67 \%$ of the refusers). "Fear of corticosteroids" specifically was the reason for nonparticipation in $8 \%$ of the refusers on the basis of "dislike of medication".

We concluded that a specific fear of corticosteroids was not a major obstacle for early intervention with inhaled corticosteroids.

Eur Respir J 1998; 11: 1178-1181.
*Dept of General Practice and Social Medicine, and **Dept of Pulmonology, Dekkerswald, University of Nijmegen, The Netherlands.

Correspondence: P.M. van Grunsven

Dept of General Practice

University of Nijmegen

P.O. Box 9101

6500 HB Nijmegen

The Netherlands

Fax: 31243617084

Keywords: Asthma

chronic obstructive pulmonary disease

fear of corticosteroids

general practice

inhaled corticosteroids

nonparticipation

Received: May 51997

Accepted after revision December 151997
Inhaled corticosteroids are considered as first-line treatment in asthma [1].Treatment with inhaled corticosteroids in adult patients with newly detected asthma has been shown to preserve the lung function [2]. In chronic obstructive pulmonary disease (COPD), inhaled corticosteroids may prove to be beneficial to subgroups of COPD patients in the short-term [3], but the long-term effects are still under investigation [4]. To be able to treat asthma and COPD at an "early" stage, detection of subjects with few symptoms might be necessary.

Inhaled corticosteroids are promoted for their relative safety, though local side-effects, such as hoarseness and oral candidiasis, and when used in high doses, also systemic side-effects such as suppression of serum cortisol levels, have been described [5]. In their study, BosLey et al. [6] discussed psychological factors associated with poor compliance in asthma. They reported that in some asthmatic patients an unjustified fear of corticosteroids or an overemphasis of the side-effects of corticosteroids have been recognized as a possible reason for underusage of these drugs. We hypothesized that "fear of corticosteroids" was the main reason for nonparticipation in our large Detection, early Intervention and Monitoring programme with inhaled corticosteroids in COPD and Asthma ("DIMCA") study.

\begin{abstract}
Methods
In 1991, a random sample of 1,749 apparently healthy adult subjects from 10 general practices in the area of Nijmegen, the Netherlands were invited by letter to participate in a screening programme on signs and symptoms of asthma and COPD. Six hundred and four subjects with mild signs/symptoms were subsequently invited to participate in a $2 \mathrm{yr}$ monitoring programme with quarterly lung function measurements. Two hundred and fifty two patients showed an increased lung function decline or bronchial hyperresponsiveness during the study period and they were invited by letter to participate in one of three randomized, double-blind, placebo-controlled intervention trials with an inhaled corticosteroid (fluticasone, $500 \mu \mathrm{g}$ daily). Subjects could only participate in one trial.

"Drug intervention 1" (duration $1 \mathrm{yr}$ ) included patients selected within 6 months of monitoring with undetected COPD. "Drug intervention 2" (duration 2 yrs) started after 1 $\mathrm{yr}$ of monitoring and included patients with a rapid decline in lung function and signs of bronchial hyperresponsiveness.
\end{abstract}


After the 2 yr monitoring period, patients with a moderately increased decline in lung function or with signs of bronchial hyperresponsiveness were included in "Drug intervention 3" (duration $1 \mathrm{yr}$ for patients with bronchial hyperresponsiveness and 2 yrs for patients with an increased decline in lung function). In the letters of invitation for the screening, monitoring and trials, the reason for selection was explained. Subjects invited for the trials were also informed in writing about the effects and possible side-effects of fluticasone. Written informed consent was obtained from all participants of the trials. Refusers were defined as subjects who were considered eligible for the screening, monitoring or one of the drug interventions, but who actively refused to participate after a mailing and one phone call, urging participation.

\section{Measurements}

In 1996, all refusers received by mail a multiple choice questionnaire concerning the reasons for nonparticipation (table 1). The questionnaire had been developed specifically for this study. Subjects were allowed to give more than one reason for nonparticipation. The final question in the questionnaire asked whether the decision to not participate would change if this programme was not an experiment but part of routine medical care. The refusers who did not respond to the questionnaire were sent one reminder. In order to gain more specific details about the reasons for refusal, refusers who had given permission in the questionnaire were phoned again and reasons for refusal explored in a structured standardized interview.

\section{Results}

The refusal rates were: $34 \%$ (95\% confidence interval (CI) $32-36 \%$ ) for the screening; $25 \%$ (95\% CI 21-29\%) for the monitoring; 35\% (95\% CI 23-49\%) for Drug intervention $1 ; 33 \%$ (95\% CI 23-44\%) for Drug intervention 2; and 28\% (95\% CI 20-37\%) for Drug intervention 3. Refusers did not differ from participants with respect to age or sex. The refusers of the monitoring part had a higher level of education than the participants.

Two hundred and sixteen $(52 \%)$ of the 411 subjects who were sent a questionnaire completed and returned the questionnaire immediately. Another 28 (7\%) subjects responded after a reminder (table 1). The overall response rates in the different stages were 48-94\%. The main reason for refusing to participate in one of the stages of "DIMCA" was the absence of respiratory symptoms (33$67 \%$ of the refusers). Time constraints were mentioned by $5-49 \%$ of the refusers. Additional in-depth interviews in 46 subjects identified the fact that work and children were critical reasons for nonparticipation. Dislike of testing or research was stated by $8-49 \%$ of all refusers.

For those invited to one of the three drug interventions, dislike of using medication emerged as the most important reason for nonparticipation (33-67\% of the subjects). Twenty three of the intervention group subjects were interviewed in more depth. General dislike of medication and general worries concerning side-effects were mentioned most often $(15(65 \%)$ of the refusers to intervention). Only $2(8 \%)$ subjects mentioned fear of (side-effects by) using corticosteroids specifically. Finally, $54 \%$ of all refusers stated that they would participate in a project like "DIMCA" if it was part of routine medical care.

Table 1. - The response to the postal questionnaire mailed to all refusers of the Detection, early Intervention and Monitoring programme on Chronic obstructive pulmonary disease and Asthma ("DIMCA" project), and the reasons for refusing to participate

\begin{tabular}{|c|c|c|c|c|c|c|c|c|c|c|c|c|c|c|c|}
\hline & \multicolumn{3}{|c|}{$\begin{array}{l}\text { Refusers of } \\
\text { screening } \\
(\mathrm{n}=506)\end{array}$} & \multicolumn{3}{|c|}{$\begin{array}{l}\text { Refusers of } \\
\text { monitoring } \\
(\mathrm{n}=151)\end{array}$} & \multicolumn{3}{|c|}{$\begin{array}{l}\text { Refusers of drug } \\
\text { intervention } 1 \\
(\mathrm{n}=19)\end{array}$} & \multicolumn{3}{|c|}{$\begin{array}{l}\text { Refusers of drug } \\
\text { intervention } 2 \\
(n=26)\end{array}$} & \multicolumn{3}{|c|}{$\begin{array}{l}\text { Refusers of drug } \\
\text { intervention } 3 \\
(\mathrm{n}=33)\end{array}$} \\
\hline & & $\begin{array}{c}\text { Male } \\
\%\end{array}$ & $\begin{array}{l}\text { Age } \\
\text { yrs }\end{array}$ & & $\underset{\%}{\mathrm{Male}}$ & $\begin{array}{l}\text { Age } \\
\text { yrs }\end{array}$ & & $\underset{\%}{\text { Male }}$ & $\begin{array}{l}\text { Age } \\
\text { yrs }\end{array}$ & & $\begin{array}{c}\text { Male } \\
\%\end{array}$ & $\begin{array}{l}\text { Age } \\
\text { yrs }\end{array}$ & & $\underset{\%}{\text { Male }}$ & $\begin{array}{l}\text { Age } \\
\text { yrs }\end{array}$ \\
\hline Refusers mailed & 208* & $\begin{array}{c}39 \\
(\mathrm{n}=99)\end{array}$ & $\begin{array}{l}49 \pm 14 \\
(\mathrm{n}=99)\end{array}$ & $125^{+}$ & 31 & $46 \pm 13$ & 19 & 39 & $46 \pm 12$ & 26 & 27 & $45 \pm 14$ & 33 & 42 & $46 \pm 11$ \\
\hline Removed/died & 32 & $\begin{array}{l}\text { No } \\
\text { data }\end{array}$ & $\begin{array}{l}\text { No } \\
\text { data }\end{array}$ & 16 & 25 & $39 \pm 10$ & 0 & - & - & 0 & - & - & 2 & 0 & $50 \pm 9$ \\
\hline $\begin{array}{l}\text { Nonresponders } \\
\text { (after reminder) }\end{array}$ & 77 & $\begin{array}{l}\text { No } \\
\text { data }\end{array}$ & $\begin{array}{l}\text { No } \\
\text { data }\end{array}$ & 28 & 21 & $43 \pm 13$ & 7 & 43 & $53 \pm 10$ & 5 & 40 & $35 \pm 11$ & 0 & - & - \\
\hline $\begin{array}{l}\text { Responders } \\
\text { (after reminder) }\end{array}$ & 99 & 39 & $49 \pm 14$ & 81 & 35 & $48 \pm 13$ & 12 & 33 & $42 \pm 11$ & 21 & 24 & $48 \pm 13$ & 31 & 45 & $46 \pm 11$ \\
\hline \multicolumn{16}{|c|}{ Reasons for refusing to participate } \\
\hline No complaints & \multirow{3}{*}{\multicolumn{3}{|c|}{$\begin{array}{l}41(41) \\
29(29) \\
49(49)\end{array}$}} & \multicolumn{3}{|c|}{$30(37)$} & \multicolumn{3}{|c|}{$4(33)$} & \multicolumn{3}{|c|}{$14(67)$} & \multicolumn{3}{|c|}{$14(45)$} \\
\hline Lack of time & & & & \multicolumn{3}{|c|}{$40(49)$} & \multicolumn{3}{|c|}{$\begin{array}{l}5(42) \\
1(8)\end{array}$} & \multicolumn{3}{|c|}{$1(5)$} & \multicolumn{3}{|c|}{9 (29) } \\
\hline $\begin{array}{l}\text { Dislike of testing } \\
\text { or research }\end{array}$ & & & & & $18(2$ & & & $1(8)$ & & & $3(14)$ & & & $8(26)$ & \\
\hline $\begin{array}{l}\text { Dislike of } \\
\text { medication }\end{array}$ & \multicolumn{3}{|c|}{ Not asked } & \multicolumn{3}{|c|}{ Not asked } & \multicolumn{3}{|c|}{$4(33)$} & \multicolumn{3}{|c|}{$14(67)$} & \multicolumn{3}{|c|}{$14(45)$} \\
\hline Other reasons $\$$ & \multicolumn{3}{|c|}{$35(35)$} & \multicolumn{3}{|c|}{$51(63)$} & \multicolumn{3}{|c|}{$5(42)$} & \multicolumn{3}{|c|}{$13(62)$} & \multicolumn{3}{|c|}{$18(58)$} \\
\hline
\end{tabular}

Age data are presented as mean \pm SD. Data concerning reasons for refusal to participate are presented as absolute number and percentage of responders in parenthesis. *: unfortunately, personal data of 298 nonresponders to the original invitation for the screening were not available; +: 26 refusers of monitoring were not contacted by mail for practical reasons; \#: only the refusers of the intervention group were asked; s: including "no transport", "family circumstances", "forgot the reason for refusal", "other illness prior to the study/ pregnant", "fear the study would show a disease", "long-term duration of study". 


\section{Discussion}

The absence of pulmonary symptoms, lack of time and dislike of medication were the main reasons for refusal to participate in an early detection and intervention programme with inhaled corticosteroids in asthma and COPD ("DIMCA" project). A specific "fear of corticosteroids" was found to be a relatively minor reason for refusal.

In every step of the "DIMCA" project, one out of every three subjects eligible did not participate. This rate is comparable with nonparticipation rates in several screening programmes in older patients concerning breast or uterine cervical cancer, colonic cancer and coronary heart disease, ranging 20-69\% [7].

Only those subjects who gave permission to be phoned for additional information about their refusal were phoned. Therefore, the in-depth interview results concerning the determinants of refusal, including the fear of corticosteroids, may have been distorted in some way.

The absence of pulmonary complaints was a main reason for refusal to enter one of the three parts of the project. Absence of complaints is likely to be an understandable reason for absence of motivation. In a colorectal cancer screening programme $83 \%$ of the refusers found the procedure unnecessary, because there were no symptoms [8]. Lack of time is mentioned as an important reason for refusal to participate in screening studies [9-14]. In the present study, one out of three refusers cited lack of time, especially due to work and family commitments. A possible solution to this problem may be flexibility in time of appointment (evening, weekend). Dislike of the test is one of the main reasons for nonparticipation in preventive screening programmes $[9,10,14,15]$. In two gynaecological mass screening programmes, refusers thought the examinations were more unpleasant compared to the participants $[10,15]$. In the present study, only a few refusers had a specific aversion to the lung function tests.

The present study showed a high rate of general dislike of medication. This is not an unexpected finding, because most of the subjects of the "DIMCA" study showed only mild bronchial symptoms. Several studies have shown that the fear of side-effects of drugs is a common reason for refusal to be treated with hormonal replacement the-rapy [16-18], diazepam [9] and aspirin [20], or to be vaccinated [21-22]. The general aversion to drugs in the present study was accompanied by only a small rate of specific fear of inhaled corticosteroids. It is our experience that in clinical practice patients often do not consider inhaled drugs as "real medicines" like tablets. Furthermore, inhaled corticosteroids may not have the same impact as oral prednisone, which is popularly known as a "kill or cure remedy".

Results of the first drug intervention study of the "DIMCA" project show there are indications that treatment with inhaled corticosteroids may preserve the lung function in undetected COPD [23]. However, the costs and effectiveness of early detection and preventive treatment with inhaled corticosteroids in (largely asymptomatic) asthma and COPD have to be weighed carefully before a large scale prescription of inhaled corticosteroids may be advisable.

This is the first (experimental) study describing obstacles in implementing a screening and early intervention strategy with inhaled corticosteroids in chronic obstruc- tive pulmonary disease and asthma in general practice. The absence of pulmonary complaints and lack of time as well as a general resistance to medication were the main determinants of nonparticipation in a relatively healthy and active population. However, in contrast to our hypothesis, doctors do not have to fear that inhaled corticosteroids in particular are an obstacle to participation in early pharmacological intervention in asthma or chronic obstructive pulmonary disease.

\section{Reference}

1. National Heart, Lung, and Blood Institute. Expert Panel on the Management of Asthma: guidelines for the diagnosis and management of asthma. J Allergy Clin Immunol 1991; 88: s425-s534.

2. Haahtela T, Jarvinen M, Kava T, et al. Effects of reducing or discontinuing inhaled budesonide in patients with mild asthma. N Engl J Med 1994; 331: 700-705.

3. Schayck CP van, Grunsven PM van, Dekhuijzen PNR. Do patients with COPD benefit from treatment with inhaled corticosteroids? Eur Respir J 1996; 9: 19691972.

4. Siafakas NM, Vermeire P, Pride NB, et al. Optimal assessment and management of chronic obstructive pulmonary disease (COPD): ERS consensus statement. Eur Respir J 1995; 8: 1398-1420.

5. Geddes DM. Inhaled corticosteroids: benefits and risks. Thorax 1992; 47: 404-407.

6. Bosley CM, Fosbury JA, Cochrane GM. The psychological factors associated with poor compliance with treatment in asthma. Eur Respir J 1995; 8: 899-904.

7. Carter WB, Elward K, Malmgren J, Martin ML, Larson E. Participation of older adults in health programs and research: a critical review of the literature. Gerontologist 1991; 31: 584-592.

8. Vernon SW, Acquavella JF, Yarborough CM, Hughes JI, Thar WE. Reasons for participation and nonparticipation in a colorectal cancer screening program for a cohort of high risk polypropylene workers. J Occup Med 1990; 32: 46-51.

9. Spoth R, Redmond C. Study of participation barriers in family-focused prevention: research issues and preliminary results. Quarterly of Community Health Education 1992-1993; 13: 365-388.

10. Sansom CD, MacInerney J, Oliver V, Wakefield J. Differential response to recall in a cervical screening programme. Br J Prev Soc Med 1975; 29: 40-47.

11. Hansen BF, Johansen JR. Dental visits, teeth remaining and prosthetic appliances in a Norwegian urban population. Community Dent Oral Epidemiol 1976; 4: 176181.

12. Neale AV, Demers RY, Herman S. Compliance with colorectal cancer screening in a high-risk occupational group. J Occup Med 1989; 31: 1007-1012.

13. Cameron PW. Participation by health professional students in tuberculin screening. J Am College Health 1986; 34: 288-289.

14. Dent OF, Bartrop R, Goulston KJ, Chapuis PH. Participation in faecal occult blood screening for colorectal cancer. Soc Sci Med 1983; 17: 17-23.

15. Hesselius I, Lisper HO, Nordstrom A, Anshelm-Olson B, Odlund B. Comparison between participants and nonparticipants at a gynaecological mass screening. Scand J Soc Med 1975; 3: 129-138. 
16. Mattsson LA, Stadberg E, Milsom I. Management of hormone replacement therapy: the Swedish experience. Eur J Obstet Gynecol Reprod Biol 1996; 64: s3-s5.

17. Limouzin-Lamothe MA. What women want from hormone replacement therapy: results of an international survey. Eur J Obstet Gynecol Reprod Biol 1996; 64: s21s24.

18. Spinelli A, Grandolfo M, Donati S, Medda E. Family planning in Italy. Adv Contracept 1993; 9: 153-160.

19. Balmer R, Battegay R, von Marschall R. Long-term treatment with diazepam. Investigation of consumption habits and the interaction between psychotherapy and psychopharmacotherapy: a prospective study. Int Pharmacopsychiatry 1981; 16: 221-234.
20. Hutton JD, Wilkinson AM, Neale J. Poor participation of nulliparous women in a low-dose aspirin study to prevent pre-eclampsia. NZ Med J 1990; 103: 511-512.

21. Celentano DD, Beyrer C, Natpratan C, et al. Willingness to participate in AIDS vaccine trials among high-risk populations in northern Thailand. AIDS 1995; 9: 10791083.

22. Briggs MJ, Thomas J. Obstacles to hepatitis B vaccine uptake by health care staff. Public Health 1994; 108: 137-148.

23. Tirimanna PRS, van Grunsven PM, van den Boom G, et $a l$. The effectiveness of inhaled steroids as first-line therapy in the treatment of newly detected asthma in the open population. Eur Respir J 1996; 9: 54s. 